\title{
Dietrich Beyrau
}

\section{Das bolschewistische Projekt als Entwurf und als soziale Praxis}

\section{Einführung}

Die utopischen Aspekte im sowjetischen Sozialismus sind seit langem ein prominenter Gegenstand der historischen Forschung. Titel wie „Utopie an der Macht oder ${ }_{n}$ Vollstreckter Wahn " verweisen hierauf ${ }^{1}$. Diese Studien beziehen sich auf die "Ideologie“ als Politik und Gesellschaft gestaltende Kraft. Sie wollten damit auch die totalitären Ambitionen der politischen Führung und manchmal ihre Brechung an einer widerständigen Realität beschreiben.

Die sozialhistorische Forschung seit den siebziger Jahren hat mit ihrer Wendung gegen das Totalitarismusmodell die politischen und utopischen Elemente aus der Analyse der Geschichte der Sowjetunion weitgehend ausgeblendet, auch wenn Elemente und Instrumente der gewalttätigen Transformation zum Thema gemacht wurden; genannt seien die Kulturrevolution um 1928, die Säuberungen oder der Terror ${ }^{2}$. Seit etwa einem Jahrzehnt tauchen die utopischen und religiösen Ingredienzen des bolschewistischen Projektes mit Rückgriff auf Eric Voegelin, Jacob Talmon, Nikolaj Berdjaev und Karl Löwith wieder auf, nun allerdings mit kulturhistorischen Methoden angereichert ${ }^{3}$. Man könnte von einer kulturhistorischen Aufladung der Totalitarismustheorie sprechen. Am weitesten gehen jene Konzepte, die von der alternativlosen Formierung eines stalinistischen Subjekts ausgehen, gefangen in den Dogmen und in der Sprache offizieller Rede 4 . Im Vor-

1 Michael Heller, Alexander Nekritsch, L'utopie au pouvoir. Histoire de l'U.R.S.S. de 1917 à nos jours (Paris 1981). Deutsch: Geschichte der Sowjetunion, Bd. 1-2 (Königstein Ts. 1981); Martin Malia, Vollstreckter Wahn. Rußland 1917-1991 (Stuttgart 1994).

2 Vom sozialhistorischen Zugang geprägt (und dortiger Literaturnachweis): Manfred Hildermeier, Geschichte der Sowjetunion 1917-1991. Entstehung und Niedergang des ersten sozialistischen Staates (München 1998); Ronald G. Suny, The Soviet Experiment. Russia, the USSR, and the Successor States (New York 1998); kulturhistorische Ansätze nutzend: Dietrich Beyrau, Petrograd, 25.Oktober 1917. Die russische Revolution und der Aufstieg des Kommunismus (München 2001); im folgenden zitiert: Beyrau, Petrograd.

${ }^{3}$ Exemplarisch vgl. Igal Halfin, From Darkness to Light. Class, Consciousness and Salvation in Revolutionary Russia (Pittsburgh 2000).

${ }^{4}$ So schon Czestaw Mitosz, Verführes Denken (Frankfurt a.M. 1974); Leszek Kolakowski, 
dergrund steht dabei nicht mehr die Ideologie als ein mehr oder minder kohärentes System von Doktrinen, sondern eine Vielzahl von utopischen und visionären Zielvorstellungen, die zur Umgestaltung der Gesellschaft und ihrer Individuen antrieben. Je nach Standpunkt konnte dies als Lust am Experiment oder als Vorwegnahme einer totalitären Praxis gedeutet werden 5 .

Die bolschewistischen Zukunftsvorstellungen sollten eine ungeheure Dynamik entfalten. Mit Bezug auf ihre destruktiven Dimensionen hat Gerd Koenen sie als "Utopie der Säuberung " beschrieben ${ }^{6}$. In Gestalt ökonomischer Planungen, den Fünfjahrplänen, realisierten sie die "Rekonstruktion" von Gesellschaft, Raum und Natur. Die russischen Revolutionäre verlegten ihre Zukunftsvisionen nicht auf einen "roten Stern" - wie in der klassischen Utopie -, dies taten sie bestenfalls als Literaten ${ }^{7}$. Als Anhänger eines ${ }_{n}$ wissenschaftlichen Sozialismus “, die sich vom "utopischen" Sozialismus abgrenzten, stützten sich die Bolschewiki auf Analysen von Entwicklung, Fortschritt und von anhaltenden Transformationsprozessen. Dies geschah mit dem Anspruch, soziale Realität und ihre "Gesetzmäßigkeiten“ in der Tradition von Marx und Engels wissenschaftlich zu erklären. Damit glaubten sie, auch über die richtigen Zielvorstellungen zu verfügen. Den objektiven ökonomischen Entwicklungsgesetzen stand das subjektive Element des Klassenkampfes als dynamisches, bewußtseinformendes Medium zur Seite, das den historisch-politischen Prozeß vorantrieb. Eine ganz auf Polarisierung und Kampf setzende Strategie, die von der fundamentalen Ablehnung der bestehenden Zustände ausging, schien das geeignete Mittel zu sein, um die von der Bourgeoisie angestoßene Entwicklung ihrem harmonischen Ende zuzuführen. Das Proletariat würde die Bourgeoisie beerben und galt als das zukünftige Subjekt der neuen Gesellschaft.

An den Schriften Lenins und Stalins fällt auf, daß Kontingenz, Subjektivität und Freiheit und damit dic Möglichkeit des nicht nur taktischen Irrtums geleugnet werden. In den obsessiven Vorstellungen vom Feind schlägt sich die Gewiß-

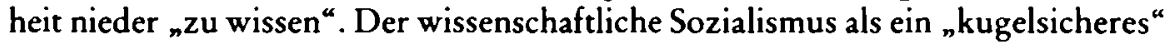
System von Erkenntnissen und Erkenntnisinstrumenten erschloß ihnen die $\mathrm{Ge}-$ setzmäßigkeiten historischer Entwicklung. Träger dieses Wissens waren die intellektuellen Berufsrevolutionäre, später das Abstraktum „die Partei“.

In der bolschewistischen Analyse von Vergangenheit und Gegenwart läßt sich von einem offenen und von einem eher verborgenen oder einem Nebentext ausgehen: Auf der einen Seite steht eine positivistisch-materialistischen Kriterien verpflichtete Deutung - etwa Lenins Analyse der „Entwicklung des Kapitalismus in

Der Mensch ohne Alternative (München 1969); zuletzt Jochen Hellbeck (Hrsg.), Tagebuch aus Moskau 1931-1939 (München 1996).

${ }_{5}$ Richard Stites, Revolutionary Dreams. Utopian Vision and Experimental Life in the Russian Revolution (Oxford 1989); Stefan Plaggenborg, Revolutionskultur. Menschenbilder und kulturelle Praxis in Sowjetrußland zwischen Oktoberrevolution und Stalinismus (Köln 1996).

6 Gerd Koenen, Utopie der Säuberung. Was war der Kommunismus? (Berlin 1998).

7 Alexander Bogdanov, Roter Stern. Ein utopischer Roman (Darmstadt 1982). 
Rußland" mit dem Nachweis von Klassenbildung selbst auf dem Dorf -, auf der anderen Seite finden sich heilsgeschichtlich aufgeladene Schriften, wie Lenins "Staat und Revolution" (1917) oder der Stalinsche "Kurze Lehrgang", die amtli-

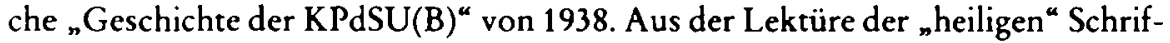
ten haben sich in der Historiographie ganz unterschiedliche Lesarten der bolschewistischen Ideen und ihrer Folgen ergeben. Suchten die einen nach den soziologisch-rationalen Elementen im Bolschewismus und nach den Gründen seiner heillosen Verstrickung in die Widrigkeiten sozialer Realitäten in Rußland ${ }^{8}$, so suchten die anderen nach Neben- oder gar Subtexten, um daraus seine irrationalen Elemente zu erklären'. Denn auch in der bolschewistischen Bewegung existierten Neben- und Unterströmungen, die sich unter dem Einfluß und in der gleichzeitigen Abwehr von Nietzsche, des Neukantianismus und "Idealismus" - so die russische Terminologie - um eine religiöse Aufladung und Überhöhung der revolutionären Bewegung bemühten. Obwohl von Lenin heftig bekämpft, sollten sie später in gebrochener Weise Eingang in die Proletkultbewegung, in die Semantik des Bürgerkrieges und nicht zuletzt in den Lenin- und Stalinkult finden ${ }^{10}$.

Dic Katastrophe des Ersten Weltkrieges als Beleg für die Verworfenheit von Kapitalismus und Imperialismus hat den heilsgeschichtlich unterfütterten Glauben an den Fortschritt bestätigt. Dabei mag der Widerspruch zwischen den Visionen und einer erbärmlichen Realität die ohnehin im Bolschewismus angelegten polarisierenden und manichäischen Deutungen intensiviert haben.

Bezogen auf die kultischen Elemente, die sich zunächst in der Partei und dann auch in der Gesellschaft mit dem Lenin- und dem Stalinkult etablierten, mag es berechtigt sein, vom Bolschewismus als politischer Religion zu sprechen ${ }^{11}$. Die kultischen und manchmal offenen, manchmal eher verborgenen heilsgeschichtlichen Elemente scheinen mir aber nicht zentral genug zu sein, um die Herrschaft Lenins und Stalins darauf zu reduzieren. Auch der Utopiebegriff verfehlt insofern zentrale Elemente der sowjetischen Geschichte, als „Utopie“ im herkömmlichen Sinn den Entwurf einer perfekten Ordnung jenseits von Zeit und Raum, also seine Irrealität meint. Dem Marxismus sowjetischer Prägung aber lag eine Deutung historisch zielgerichteter Entwicklung zugrunde, in deren Kontinuum er sich einordnete.

8 Vgl. exemplarisch: Werner Hofmann, Stalinismus und Antikommunismus. Zur Soziologie des Ost-West-Konflikts (Frankfurt a. M. 1970).

${ }^{9}$ Alain Besancon, The Intellecrual Origins of Leninism (aus dem Französischen, Oxford 1981); im folgenden zitiert: Besancon, Intellectual Origins.

10 Zusammenfassend vgl. Leszek Kotakowski, Die Hauptströmungen des Marxismus, Bd. 2 (München 1977); im folgenden zitiert: Kolakowski, Hauptströmungen. Bernice Glatzer Rosenthal (Hrsg.), Nietzsche and Soviet Culture. Ally and Adversary (Cambridge 1994).

11 Benno Ennker, Die Anfänge des Leninkults in der Sowjetunion (Köln 1997); im folgenden zitiert: Ennker, Anfänge des Leninkults. Ders., Politische Herrschaft und Stalinkult 1929 1939, in: Stefan Plaggenborg (Hrsg.), Stalinismus. Neue Forschungen und Konzepte (Berlin 1998); Victoria Bonnell, Iconography of Power. Soviet Political Posters under Lenin and Stalin (Berkeley 1997); Jan Plamper, The Stalin Cult in the Visual Arts, 1929-1953 (Ph.D. diss. Berkeley 2001). 
Deshalb soll hier nicht von Utopie und nicht von politischer Religion, sondern vom Bolschewismus als Projekt die Rede sein. „Projekt" hebt ab auf die Verzeitlichung und den Prozeß der Realisierung des Visionären und Utopischen im Raum. Dieser Begriff betont die mobilisierenden, menschliches Denken und Handeln strukturierenden Funktionen der Deutung von Gegenwart und Zukunft. "Projekt" ist kein eingeführter soziologischer Begriff. Er meint im engeren Sinn den Entwurf auf dem Reißbrett, im eher metaphorischen Sinn den Entwurf in den Köpfen und seinen Niederschlag in den Schriften und Handlungen von Akteuren, die sich das Projekt zueigen machen und es zu verwirklichen suchen. Unter diesem Aspekt sollen hier jene Elemente hervorgehoben werden, die maßgeblich politische Entscheidungen und vor allem die politische Praxis auch jenseits des engeren Zirkels der bolschewistischen Führung bestimmt haben.

Zunächst seien einige methodische Vorbemerkungen erlaubt. Im vorliegenden Text figuriert Lenin als ein zentraler Bezugspunkt des bolschewistischen Projekts. Er lieferte nicht nur wichtige Stichworte für den revolutionären Prozess und konkretisierte sie in programmatischen Erklärungen. Er blieb für die folgenden Generationen sowjetischer Führer, aber auch des Fußvolks in der Partei und selbst in der Bevölkerung aktuell, er wurde immer wieder neu gelesen und aktualisiert. Daß sich der Lenin Stalins erheblich von dem Trockijs, Chruščevs, Brežnevs oder Gorbačevs unterschied, versteht sich von selbst. Lenin steht aber nur für eine ganze Generation revolutionärer Intellektueller und Aktivisten, die trotz permanenter Streitigkeiten untereinander das bolschewistische Projekt mitgestalteten, auch wenn sie seine Opfer wurden oder sich selbst eher als Mitläufer verstanden bzw. als solche eingeordnet wurden.

Als wichtigste Stichwortgeber seien hier neben Lenin Trockij, Stalin, Aleksandr Bogdanov, Emeljan Jaroslavskij, Anton S. Makarenko, Vladimir Majakovskij, Aleksej N. Tolstoj und Maksim Gor'kij, Aleksej Gastev und so „bürgerliche“ Wissenschaftler wie Ivan P. Pavlov genannt. Diese Namen sollen nur andeuten, welche Vielfalt von Visionen und Programmen zusammenflossen, aber auch welche Vielfalt von Lebenswelten durch das bolschewistische Projekt abgedeckt wurden. Lenin, Trockij und Stalin stehen jeder auf seine Weise für die sozialistische Transformation von Staat, Gesellschaft und Wirtschaft. In Majakovskij verkörperte sich das Pathos der Revolution. Jaroslavskij steht für den anti-religiösen Kampf und die gleichzeitige Übertragung einer kämpferisch-heilsgeschichtlichen Deutung auf das bolschewistische Projekt, wie sie im "Kurzen Lehrgang der Geschichte der KPdSU(B) “ zerniert wurde. Bogdanov, Gor'kij und Gastev zelebrierten eine neue proletarisch-maschinelle, urbane und prometheisch-heroische Kultur des "neuen Menschen ", dessen Lebenssinn auf die Realisierung einer sozialjstisch-industriellen Kultur hinauslaufen sollte. Gor'kij, Makarenko, Gastev und nicht zuletzt Pavlov stehen für den Entwurf des disziplinierten, eindimensionalen und funktionierenden Produzenten mit durchaus utopischen Elementen. Tolstoj und - unter anderem - auch Stalin betrieben neben vielen "umgeschmiedeten “ bürgerlichen Literaten und Historikern die Etablierung einer "vaterländischen", sowjetpatriotisch konnotierten Dimension des Sozialismus. Mit seiner patrio- 
tisch-sakralen Aufladung wurden neotraditionalistische Elemente in das bolschewistische Projekt integriert ${ }^{12}$. Auch hierbei konnte man sich noch auf Lenin beziehen.

Die Vielfalt, die Abfolge, oft genug auch die Inkohärenz der Visionen, Zukunftsentwürfe und Programme erklären ihre Anziehungskraft auf ganz unterschiedliche Bevölkerungsgruppen und Milieus inner- wie außerhalb der Sowjetunion, aber auch ihre Konfliktträchtigkeit, weil sie immer „direktive“ Geltung beanspruchten. Diese Wechsel reagierten zwar auf innere und äußere Konstellationen, sie wurden aber in ein intellektuelles Repertoire eingefügt, das in vielen Varianten im bolschewistischen Projekt, nicht zuletzt bei Lenin, vorgegeben war.

Wenn vom Bolschewismus als „Utopie an der Macht“ oder als „vollstrecktem Wahn" die Rede ist, so müßte in seine Darstellung und Analyse auch die soziale Diffusion und sein Durchgang durch soziale Filter in den verschiedenen Milieus thematisiert werden, d.h. seine Aneignung, Umformung, Instrumentalisierung oder auch die Verwerfung einzelner seiner Elemente durch die Akteure und Objekte der Transformation. Angesichts der Exekutivschwäche selbst des Stalinregimes und angesichts der strukturellen Resistenzen bleibt die Frage der Reichweite zentraler Normen und Vorgaben, bleiben auch die Spielräume der Akteure in den unterschiedlichen Handlungsfeldern weiterhin umstritten ${ }^{13}$. Dabei besteht keine Einigkeit darüber, was dem bolschewistischen Projekt, was systemneutraler oder transnationaler Modernisierung und was schließlich der Transformation spezifisch russischer Volks- und Staatstradition zuzuschreiben wäre ${ }^{14}$.

Aus Platzgründen kann im vorliegenden auf all diese Aspekte nur in Andeutungen eingegangen werden. Hier richtet sich die Aufmerksamkeit statt dessen vor allem auf die Verbindung des bolschewistischen Projekts mit sozialen Interessen. Erst diese Verbindung verlieh ihm Dauer und normative Kraft, wie sich noch in der evolutionären Phase nach 1956 zeigen sollte.

12 Katerina Clark, The Soviet Novel. History as Ritual (Chicago 1985); Hans Günther, Der sozialistische Übermensch. M. Gor'kij und der sowjetische Heldenmythos (Stuttgart 1992). 13 Stephen Kotkin, Magnetic Mountain. Stalinism as a Civilization (Berkeley u.a. 1995); im folgenden zitiert: Kotkin, Magnetic Mountain. Sarah Davies, Popular Opinion in Stalin's Russia. Terror, Propaganda and Dissent, 1934-1941 (Cambridge 1997); Sheila Fitzpatrick, Everyday Stalinism. Ordinary Life in Extraordinary Times. Soviet Russia in the 1930s (New York 1999). Siche zum „Widerstand“ im Stalinismus die Beiträge in: Kritika 1 (2000).

14 Die Betonung spezifisch russischer Volks- und Herrschaftskultur betonen zuletzt: Orlando Figes, A People's Tragedy. The Russian Revolution 1891-1924 (London 1996); s.a. Edward L. Keenan, Muscovite Political Folkways, in: The Russian Review 45 (1986) 115181. Zu der Betonung des spezifisch "kommunistischen“ Aspektes s. die Beiträge "Unterdrückung, Gewalt und Terror im Sowjetsystem“. Diskussionsbeiträge zum „Schwarzbuch des Kommunismus", in: Osteuropa $50(6 / 2000)$. Zu transkulturellen Aspekten: James C. Scott, Seeing like a State. How Certain Schemes to Improve the Human Conditions Have Failed (New Haven 1998); David L. Hoffmann, Yanni Kotsonis (Hrsg.), Russian Modernity. Politics, Knowledge, Practices (New York 2000); Stephen Kotkin, Modern Times: The Soviet Union and the Interwar Conjuncture, in: Kritika 2 (2001) 111-164. 
Folgende Aspekte dessen, was hier unter bolschewistischem Projekt gefaßt wird, sollen besonders hervorgehoben werden:

1. Die Volksrevolution und die Diktatur des Proletariats

2. Die Partei als Avantgarde und ihre Verbindung mit den Massen

3. Der Staat als Maschine und die Gesellschaft als Fabrik

4. Die permanente Feindmarkierung

5. Die Zivilisierungsdiktatur

6. Technikgläubigkeit und Standardisierung

7. Ausblick und Vergleich.

\section{Die Volksrevolution und die Diktatur des Proletariats}

Die Realisierung des bolschewistischen Projekts vollzog sich vor dem Hintergrund einer "plebejischen" Revolution, die fast alle Elemente bürgerlicher $\mathrm{Zu}$ kunftserwartungen zerstörte. Das alte Regime hatte bürgerliche Reformen in Gang gesetzt, allerdings nur in Ansätzen realisiert: Rechtsstaatlichkeit, Parlamentarisierung, Selbstverwaltung und Öffentlichkeit, Industrialisierung und Durchsetzung des Privatbesitzes auch auf dem Lande. Zentrale Impulse der Revolution waren - vor dem Hintergrund des Krieges und einer zusammenbrechenden Infrastruktur - "soziale Demokratie“ als direkte Volksherrschaft in Gestalt der Räte (Sowjets) und Versorgungs- und Verteilungsgerechtigkeit im Sinne einer "moralischen Ökonomie “ (E. P. Thompson). Die Herrenklasse, Kapitalismus und Imperialismus hingegen galten als Ursache allen Unglücks.

In dieser Revolution realisierte sich für Lenin die Spontaneität (stichijnost') der Arbeiterklasse und der armen Bauernschaft mit ihren Räten, Komitees und Versammlungen als "arbeitenden " Körperschaften. Die Revolution hatte endgültig "die Massen" zu Akteuren in der Politik gemacht, auch wenn dies weder zur Etablierung eines demokratischen Systems noch zu anderen Varianten von Volksherrschaft führen sollte. Aber auch unter den Bedingungen einer Parteiherrschaft blieben die Revolution und die politische Mobilisierung der Bevölkerung ein verpflichtendes Erbe. Es lebte weiter in der öffentlichen Rhetorik, in Appellen an die Bevölkerung, im Politikstil der Bolschewiki und nicht zuletzt in der Simulation von politischer Teilhabe an der Macht. So hielt man an den Sowjets - als mehr oder minder entleerten, rituelle Funktionen erfüllenden - Institutionen fest. Sie haben schließlich dem neuen Staat ihren Namen gegeben. Auch andere Institutionen und Ausprägungen sowjetischer Politik tradierten oder simulierten die Diktatur des Proletariats und Volksherrschaft. Kampagnen wurden zu einem spezifischen Merkmal sowjetischer Politik und Öffentlichkeit. Kampagnen galten als Ausdruck von Spontaneität und Partizipation der Parteimitglieder, der Werktätigen oder des Volkes ${ }^{15}$. Die Kampagnen sind zwar in der Regel aus den Milieus der

15 Siehe „Macht und öffentliche Räume im Sozialismus“. Beiträge von Jan C. Bebrends, Sandra Dablke, Lorenz Erren, Johannes Grützmacher, Malte Rolf, in: JGO 50 (2002) (H. 2). 
Partei hervorgegangen, sie hatten aber immer Initiativen, Aktivitäten und auch Enthusiasmus von unten zu demonstrieren. Im Laufe der Jahrzehnte blieb fast kein Bereich öffentlichen und manchmal auch privaten Lebens davon unberührt. In der Form von Kampagnen vollzog sich die Institutionalisierung der subbotniki, der freiwilligen Arbeitseinsätze am Sonnabend, die Schließung von Kirchen und die Entlarvung von Feinden, der Eintritt in den Kolchos ebenso wie die Durchsetzung des Abtreibungsverbots 1936, aber auch so hochpolitische Themen wie die Diskussionen um die Stalin-Verfassung. Kampagnen hatten einerseits eine camouflierende Funktion, aber sie lieferten immer auch eine Plattform für Kritik. Sie boten zudem der Führung Einblicke in die Stimmungslagen der Bevölkerung, und sie etablierten Verhaltenscodes. Ein klassisches Beispiel für die Spontaneität der Arbeiterklasse waren die Stoßarbeiter- und dann die Stachanov-Bewegung. Sie belegten den ungebremsten Aktivismus der "befreiten Arbeit“. In der StachanovBewegung verbanden sich alle Komponenten gelenkter Spontaneität, die in der Praxis ihre eigene Dynamik entfaltete: Sie mobilisierte den Klasseninstinkt und einen rüden Aufstiegswillen. Ein revolutionärer Habitus durfte sich im engeren Umfeld austoben. Denunziantentum wurde als Wachsamkeit gegen den Klassenfeind geadelt. Und zugleich sonderte man permanente Unterwerfungssignale an die Parteiführung bzw. an Stalin ab. Dies alles ließ sich als gelebte Spontaneität und Volksherrschaft, als Realisierung der Versprechen der Revolution und schließlich als Sozialismus ausgeben. Von den Profiteuren dieser Vorgänge wurde dies offensichtlich so verstanden ${ }^{16}$.

Ein weiteres Erbe der Revolution ebenso wie eine Obsession der Bolschewiki war die Essentialisierung der Klassenherkunft. Klasse war keine soziologische, sondern eine instabile sozial-moralische Kategorie. Entsprechend dem Kampagnen-Stil der Bolschewiki wurde sie zu unterschiedlichen Zeiten und in wechselnder Intensität strafend oder belohnend eingesetzt. Den positiven Pol bildeten die Arbeiter und die arme Bauernschaft, den negativen - zunächst - die Angehörigen der einst herrschenden Schichten (Adlige, gehobenes Beamtentum, Unternehmer, Kaufleute, Priester und Angehörige der kommerziellen Schichten). Aber schon 1918 verflüchtigte sich der Klassenfeind, da er in der Kategorie des Konterrevolutionärs nicht aufging; denn auch Arbeiter und arme Bauern konnten "objektiv“ Positionen des Klassenfeindes einnehmen, wie sich umgekehrt Studenten, Angestellte und Funktionäre aller Stufen, nicht zuletzt Intellektuelle, auf den Standpunkt des Proletariats oder - sicherer - auf den der Partei stellen konnten. Klassenherkunft und Klassenzuschreibung blieben bis weit in die Nachkriegszeit ein wichtiges Kriterium für die Karriere, allerdings ergänzt durch viele andere Merkmale. Zusammen blieben sie ein Denunziationen, Angst und Unsicherheit auslösender Faktor ${ }^{17}$.

16 Robert Maier, Die Stachanov-Bewegung 1935-1938 (Stuttgart 1990); Lewis H. Siegelbaum, Ronald G. Suny (Hrsg.), Making Workers Soviet. Power, Class and Identity (London 1994).

17 Alan M. Ball, Russia's Last Capitalists. The Nepmen, 1921-1929 (Berkeley 1987); Sheila Fitzpatrick, How the Mice Buried the Cat: Scenes from the Great Purges of 1937 in the Rus- 
Wie die Sowjets so blieben auch die Arbeiterklasse und - später verwässert - die Werktätigen ein zentraler legitimierender Bezugspunkt des Regimes. Nicht nur in der Propaganda wurde damit ein Versprechen der Revolution eingelöst. Denn der Terror Stalins gegen die Eliten in Partei und Staat sowie die Expansion der Apparate seit Einführung der Planwirtschaft hatten zur Folge, daß sich Angehörigen der Unterschichten vielfältige Aufstiegsmöglichkeiten boten. Insbesondere die Parteiführung nach Stalins Tod sollte sich aus diesen Gruppen rekrurieren. Die Folge war eine unter Stalin sozialisierte "volksnahe Obrigkeit ${ }^{4}$, so ein späterer Spötter ${ }^{18}$.

Ein weiterer Faktor, der den revolutionären Prozeß bestimmte und auch dem bolschewistischen Projekt zu eigen war, läßt sich mit den Begriffen Egalitätsfuror, moralische Ökonomie und Verteilungsgerechtigkeit kennzeichnen. Teils aus der Not des Krieges und Bürgerkrieges hervorgegangen, teils aber auch als Projekt vorangetrieben, leiteten der Egalitätsfuror in der Arbeiterschaft wie unter den Bauern und der bolschewistische Kontrollwahn permanente Enteignungen und Umverteilungen ein. Der Übergang zur Planwirtschaft, so chaotisch er sich vollzog, fügte sich ein in die Vision einer konjunkturfreien, gesteuerten Distributionswirtschaft, einer von der "Diktatur der Arbeiterklasse" bestimmten Wirtschaft, also einer Politökonomie im eigentlich Sinn des Wortes. Als Ausweg aus der von den Bolschewiki selbst produzierten und dann auch noch aufgebauschten Krise der NEP bot sich in der Wahrnehmung der Parteiführung unter Stalin nur der Übergang in die Planwirtschaft. Hier konnten die Ressourcen so verteilt werden, wie es der Führung angemessen schien. Zudem ließen sich (fast) alle "kapitalistischen" Elemente im Handel und in der Landwirtschaft zusammen mit dem Klassenfeind - den NEP-Leuten und den Kulaken - „liquidieren“.

Die politisch gesteuerte Industrialisierung, die Urbanisierung, die Kontrolle über die Vermarktung insbesondere des Getreides und technischer Kulturen, die erst langsam sich vollziehende Technisierung der Arbeits- und Lebenswelten waren trotz des Hungers und des Konsumverzichts der Masse der Bevölkerung als Gegenentwurf zur krisengeschüttelten kapitalistischen Welt zu verstehen. Stalin und sein enger Kreis wollten Herren und nicht Objekte der W/rtschaft sein.

Das Egalitätsversprechen der Revolution wurde durch den sozialen Aufstieg aus den Unterschichten und durch eine statusfixierende Verteilungswirtschaft eingelöst. Aufbau des Sozialismus bedeutete langfristig die Homogenisierung der Gesellschaft und Standardisierung ihrer Lebenswelten. Kurzfristig wurde die Entstehung von Hierarchien mit noch bestehenden Knappheiten oder mit der Bedrohung von außen legitimiert. Aus der einst revolutionär gewendeten "moralischen Ökonomie" war eine autoritär orientierte Tausch- und Fürsorgewirtschaft geworden, die ganz von den staatlich regulierten Wohltaten abhing. Das Verhält-

sian Provinces, in: The Russian Review 52 (1993) 299-320; Jörg Baberowski, „Die Verfasser von Erklärungen jagen den Parteiführern einen Schrecken ein “: Denunziation und Terror in der stalinistischen Sowjetunion 1928-1941, in: Friso Ross, Achim Landwebr (Hrsg.), Denunziation und Justiz (Tübingen 2000) 165-197.

18 Alexander Sinowjew, Gähnende Höhen (Zürich 1981) $536 f$. 
nis zwischen Bevölkerung und Staat konnte hierbei Elemente des Potlatsch, des symbolischen und praktischen Austauschs von Geschenken, annehmen ${ }^{19}$. Auffällig bleibt, welche Unzufriedenheit in der Gesellschaft - und hier besonders in der Klientel der Bolschewiki, der Arbeiterschaft - entstand, als die Parteiführung 1935 und 1947 von der rigiden Distributionswirtschaft abrückte20.

\section{Die Partei als Avantgarde und ihre Verbindung mit den Massen}

Es war vor allem Lenin, der das Konzept der Partei als Avantgarde des Proletariats, als intellektueller und moralischer Speicher des richtigen $W_{1 s s e n s}$ und Verhaltens, als Motor und Katalysator des revolutionären Prozesses und der sozialen Transformation entwickelt hatte. Dieses Konzept befand sich in ständiger Spannung sowohl im Verhältnis zur Volksrevolution und ihrem Erbe als auch zur nachrevolutionären Realität. Das in der Theorie so klare, in der praktischen Umsetzung aber höchst umstrittene Prinzip grundierte die innerparteilichen Auseinandersetzungen seit 1917, den Übergang zur NEP und besonders die Diadochenkämpfe nach Lenins Tod. In den Auseinandersetzungen seit 1923 ging es darum, sich des Erbes Lenins zu bemächtigen. Damit konnte man in jene Position einrükken, von der aus die Avantgarderolle der Partei und damit das bolschewistische Projekt direktiv festgelegt würde. Die Sicherung der Führung und - ganz praktisch - die Auswahl und Kontrolle der Kader waren begleitet von der Aneignung einer ganz bestimmten camouflierenden Rhetorik. Mit ihren Formeln hatte das Parteivolk nicht nur die eigene Funktion als Vorhut des Proletariats und die daraus abgeleiteten Regeln zu verinnerlichen, sondern auch die visionären Aspekte des bolschewistischen Projekts. Denn sie allein rechtfertigten ihre herausgehobene Stellung gegenüber der Gesellschaft.

Schon Lenin wurde vor und nach 1917 von sozialistischen Zeitgenossen vorgeworfen, daß er Marxismus, Partei und klassenbewußtes Proletariat in eins setzte. Dem Marxismus fiel dabei fast die Rolle eines handelnden Subjektes zu: „Indem der Marxismus die Arbeiterpartei erzieht, erzieht er die Avantgarde des Proletariats und befähigt sie damit, die Macht zu übernehmen und das ganze Volk zum Sozialismus zu führen“21. Um die Reinheit der Lehre und die Geschlossenheit der Partei zu erhalten, hatte Lenin schon vor 1917 die Partei bzw. die Berufsrevolutionäre als eine verschworene Gemeinschaft charakterisiert: „Wir schreiten als eng

19 Dietrich Beyrau, Der organisierte Autor: Institutionen, Kontrolle, Fürsorge, in: Gabriele Gorzka (Hrsg.), Kultur im Stalinismus (Bremen 1994) 60-76; Jeffrey Brooks, Thank You, Comrade Stalin! Soviet Public Culture from Revolution to Cold War (Princeton, N.J. 2000). 20 Elena Osokina, Ierarchija potreblenija. O zizni ljudej v uslovijach stalinskogo snabženija 1928-1935 (Moskau 1993); Elena Zubkova, Russia after the War. Hopes, Illusions, and Disappointments, 1945-1957 (London 1998).

21 Zitiert nach Michail Vajskopf, Pisatel' Stalin (Moskau 2001) 71; vgl. Kolakowski, Hauptströmungen, Bd. 2, $436 \mathrm{ff}$. Besancon, Intellectual Origins $233 \mathrm{ff}$. 
geschlossenes Häuflein, uns fest an den Händen haltend, auf steilem und mühevollem Weg dahin. Wir sind von allen Seiten von Feinden umgeben und müssen stets unter ihrem Feuer marschieren. "22 So konnte es auch keine Freiheit der Kritik geben, da sie nur als Einfallstor für bürgerliche Ideologien und Opportunismus diente. Daher wurden nach der Revolution die Diktatur des Proletariats und die der Bolschewiki, welche das Proletariat verkörperten, aber nicht repräsentierten, auch sprachlich miteinander gleichgesetzt. Stalin entwickelte die Rhetorik der suggestiven Verwischung bis zur Perfektion. In seiner Semantik blieben das Subjekt, das handelt, und das Objekt, das "behandelt" wird, immer im Unklaren. Denn es waren neiserne Notwendigkeiten" und abstrakte Grundsätze, welche wahlweise ihn selbst, die Partei, ihren Apparat, den Staat, das Proletariat oder das Volk zum Agieren veranlaßten. Auf diese Weise konnte auch die Parteidisziplin eine handlungsanleitende Funktion wie zuvor der Marxismus bei Lenin übernehmen: „Um die Partei vor fraktionellen Ausfällen der rechten Abweichler zu schützen, ist es notwendig, die Frage der eisernen Parteidisziplin und der unbedingten Unterordnung der Parteimitglieder unter diese Disziplin aufzuwerfen. Sonst wäre an einen ernsthaften Kampf gegen die Abweichung gar nicht zu denken. ${ }^{23}$ Diese Objektivierung politischen Handelns zeigt die Bolschewiki als Vollzieher eherner Gesetze. In der Praxis camouflierte sie persönliche Absichten und Meinungen, die als objektiv notwendig vorgestellt wurden. In der Entpersönlichung der Rede zeigt sich zugleich am deutlichsten der visionäre Aspekt bolschewistischer Politik. Sie konnte als unvermeidlich, verbindlich und "direktiv" ausgegeben werden. Sie mußte auf reale und oft genug banale Interessen des Proletariats bzw. der Werktätigen keine Rücksicht nehmen.

Das taktische Verhältnis zur Arbeiterklasse, zu den Werktätigen und schließlich zu den Massen zeigte sich in dem Widerspruch, einerseits vorzugeben, die revolutionäre Energie des Proletariats in sich aufzusaugen, andererseits das Proletariat als Objekt zu sehen, das erzogen und geleitet werden müsse. Dabei wurde zu Lenins wie zu Stalins Zeiten immer wieder an die Funktionäre appelliert, ndie Verbindung zu den Massen" nicht zu verlieren ${ }^{24}$. Wenn das Proletariat allerdings, wie während des Bürgerkrieges, sich der höheren Einsicht der Partei entzog, mangelte es nicht nur am richtigen Klassenbewußtsein, sondern das Proletariat oder die aufständischen Matrosen von Kronstadt erwiesen sich als Medien, durch die hindurch der Klassenfeind seine Machenschaften betrieb. In dieser Rhetorik erweist sich das Proletariat ebenso als Projektion wie sein unvermeidlicher Kampf für den Sozialismus. Die Parteiführung, Partei, Proletariat und Volk bilden in der bolschewistischen Semantik eine unio mystica, ein Vielheit in der Einheit, durch die reale Differenzen geleugnet oder dem üblen Willen von Widersachern angelastet werden konnten.

22 Wladimir I. Lenin, Was tun? (1902), in: ders., Werke 5 (Berlin 1955) 364.

23 Josef W. Stalin, Über die rechte Abweichung (1929), in: ders., Fragen des Leninismus (Berlin 1951) 271.

24 Whadimir l. Lenin, Über die Gewerkschaften (1920), in: ders., Werke 32 (Berlin 1961) 4. Josef W. Stalin, Referat und Schlußwort.. (1937), in: ders., Werke 14 (Dortmund 1976) 156. 
In der sozialen Praxis hatte diese Überhöhung der Partei die Entstehung eines charismatisch fixierten, autoritär-hierarchisch gegliederten Kampfverbandes mit rigiden Mechanismen der Inklusion und Exklusion zur Folge ${ }^{25}$. Die schon früh einsetzende systematische Kaderrekrutierung, Kaderkontrolle und Säuberungen sorgten für eine scharfe Trennung zwischen Gesellschaft und Partei. Sie wurde immer wieder durchbrochen durch Rekrutierungskampagnen, denen auf dem Fuße Säuberungen folgten; denn das geworbene Personal entsprach offenbar nicht den Normen des inneren Parteilebens. Aufnahmebedingungen und Ausschlußkriterien orientierten sich an der Klassenherkunft wie an Gesinnungstüchtigkeit, die als konditionierendes Element über eine längere Verweildauer oder gar den Aufstieg in der Partei entschieden. Unter soziologischem Gesichtspunkt wurde der Parteiapparat mit seinen Nomenklaturpositionen, die sich auch auf Wahlämter erstreckten, schon früh zu einem Patronagesystem mit rotierenden und fluktuierenden Kadern. „Um zu regieren, braucht man eine Armee von gestählten Revolutionären, von Kommunisten. Diese Armee gibt es, ihr Name ist Partei“, hieß es bei Lenin ${ }^{26}$. Stalin sollte diese Metapher später noch weiter ausschmücken, indem er von der Partei als einem militärischen Kampfverband mit Generälen, Offizieren, Unterführern und dem Fußvolk sprach ${ }^{27}$. Über die Fixierung auf den Führer als Inkarnation des sozialistischen Projektes und über rigide, allerdings schnell wechselnde Verhaltensnormen wurde Inklusion hergestellt. Kritik und Selbstkritik, Säuberungen und eine gelegentliche Mobilisierung des Fußvolkes konnten die Illusion von "Demokratismus“ und von Offenheit gegenüber der Bevölkerung herstellen, die aber im wesentlichen dem zu akklamieren hatte, was anderswo entschieden worden war. Das Macht- wie das Deutungsmonopol der Parteiführung standen dabei nie in Frage.

Die Rolle der Partei als Avantgarde, als Kampfverband und als Motor der gesellschaftlichen Transformation produzierte bestimmte Verhaltensmuster, welche die Parteimitglieder und vor allem die Kader in ständiger Bereitschaft halten sollten. Dies war der eigentliche Inhalt der manchmal schon habituellen Verhaltensnormen: Kritik und Selbstkritik als säubernder und mobilisierender Faktor der Selbstkorrektur, Wachsamkeit nach innen und außen, die Kader als transparente Personen mit ständigem Bekenntniszwang und der revolutionären Pose als Unterwerfungsritual, habituelle Militanz und Enthusiasmus und die aus diesen Rollenzwängen folgende Semantik. Sie hat als "neues Sprechen“, als "hölzerne“ Rede, als "bolschewistisches Sprechen“, als Parteichinesisch oder Parteijargon immer schon Aufmerksamkeit erregt. Sie sollte Eindeutigkeit herstellen, stand aber auch unter dem Verdacht, als "Maske“ zu dienen und Subtexte zu transportieren. Dies gilt für den alles verdächtigenden Blick oder „Riecher “ der kommunistischen Zeitgenossen wie für den eher forschenden Blick des Historikers ${ }^{28}$.

25 Ennker, Anfänge des Leninkultes $27 \mathrm{ff}$.

26 Wladimir I. Lenin, Referat ... (1920), in: ders., Werke 34 (Berlin 1963) 48.

27 Rede Stalins vom 3. März 1937, Materialy fevral'sko-martovskogo plenuma CK VKP(b) 1937 goda, in: Voprosy istorii 3 (1995) 14.

${ }^{28}$ Klaus-Georg Riegel, Konfessionsrituale im Marxismus-Leninismus (Köln 1985); Berthold 
Die Stilisierung zum "neuen Menschen“ strahlte auf die Gesellschaft auch auBerhalb der Partei aus, vor allem auf Angehörige nachwachsender Generationen, zumal wenn sie aus den Unterschichten aufstiegen und sich die neuen Codes aneigneten. Dies gilt aber auch für Gruppen, die aktiv in die "sozialistische Rekonstruktion " einbezogen wurden oder sich einbeziehen ließen. "Klassenfremde ${ }^{\alpha}$ Studenten erlernten die neuen Sprach- und Verhaltensstandards. Intellektuelle und Ingenieure entwarfen von sich noch im Nachhinein - je nach Situation und sprachlichen Kapazitäten - ein Bild vom kämpfenden Enthusiasten. Er wuchs mit den Aufgaben der Partei, oder er wurde durch die Partei oder gar Stalin „erzogen“. Er ging im Kollektiv auf und machte durch die Berührung mit dem Marxismus-Leninismus eine Art Erweckungserlebnis und Lernprozesse durch. Autobiographien wurden nach dem Muster eines Bildungsromans entworfen ${ }^{29}$.

Der ${ }_{n}$ sozialistische Held“, wie er im Kanon des Sozialistischen Realismus in Kunst und Belletristik entworfen wurde, galt vielfach als Maßstab der Selbstrepräsentation. Dabei war die Produktion des neuen Menschen das Ergebnis eines kollektiven Unterfangens, an dem das Publikum in vielfältiger Weise teilnahm. Die sowjetischen Klassiker - von Ostrovskijs "Wie der Stahl gehärtet wurde“ über Majakovskijs "Lenin“ bis hin zu Fadeevs "Junger Garde" - lassen sich als Ergebnis kollektiven Schaffens beschreiben. Die Autoren lieferten das Rohmaterial, die unterschiedlichen Partei- und Zensurinstanzen, aber auch mehr oder minder gesteuerte Leserkampagnen gestalteten die Helden mit, bevor sie in den sowjetischen Kanon eingehen konnten. Hier realisierte sich kollektive Kreativität ${ }^{30}$. Die Vorbildfunktion und Wirkungsmacht des sozialistischen Menschentypus zeigte sich noch in den jugendlichen Protestgruppen nach 1945. Sie nahmen Anstoß an dem Widerspruch zwischen dem sozialistischen Ideal und der Banalität einer ärmlichen Realität und organisierten sich nach dem Modell bolschewistisch-revolutionären Kampfes, wie sie es in den stalinistischen Lehrbüchern gelernt hatten ${ }^{31}$.

Unfried, Rituale von Konfession und Selbstkritik. Bilder vom stalinistischen Kader, in: Jahrbuch für Kommunismusforschung (1994) 148-164; Jan Plamper, Abolishing Ambiguity: Soviet Censorship Practices in the 1930s, in: Russian Review 60 (2000) 526-543.

29 Thomas Labusen, How Life Writes the Book. Real Socialism and Socialist Realism (London 1997); Susanne Schattenberg, Stalins Ingenieure: Lebenswelten zwischen Technik und Terror (München 2002).

30 Yuri Druzbnikov, Informer 001. The Myth of Pavlik Morozov (New Brunswick 1997); Dietrich Beyrau, Intelligenz und Dissens. Die russischen Bildungsschichten in der Sowjetunion (Göttingen 1993) 87ff; im folgenden zitiert: Beyrau, Intelligenz. Chans Gjunter (Hans Günther), Evgenij Dobrenko (Hrsg.), Socrealisticeskij kanon (Sankt Petersburg 2000).

31 Beyrau, Intelligenz 171-175. 


\section{Der Staat als Maschine und die Gesellschaft als Fabrik}

Der Mystifizierung der Partei als Verkörperung des Proletariats stand eine recht mechanistische Vorstellung vom Staat, von der Bürokratie, aber auch von der Gesellschaft gegenüber. Sie zeigt sich in Lenins Maschinenmetaphorik, bezogen auf den Staat und seine Bürokratien, und später in einer eher militaristischen Metaphorik bei Stalin. Trockij profilierte sich bereits während des Bürgerkrieges lauthals als Anhänger von Arbeitsarmeen.

In der Tradition von Marx erschien der Staat mit seiner Bürokratie und Armee lediglich als "Instrument" der herrschenden Klasse, das es zu zerbrechen gelte. Lenins Vergleich des Staates mit der Post oder sein Glaube, daß der Staat auch von einer Köchin geleitet werden könne, zeugen von einem recht begrenzten Verständnis für die Funktionen des modernen Staates, die auch am Beispiel des vorrevolutionären Rußlands hätten studiert werden können. Verwaltung und Organisation wurden auf Rechnungsführung und Kontrolle reduziert. Ihre komplizierten Regeln von Arbeitsteiligkeit und Regelhaftigkeit, von Interessenformierung und Interessendurchsetzung wurden nicht zur Kenntnis genommen. Bürokratien blieben in der bolschewistischen Wahrnehmung "Apparate“, in die das Proletariat als herrschende Klasse nur seine Befehle einzugeben hatte, wie es zuvor "die Kapitalisten “ getan hatten ${ }^{32}$. Man könnte von einer Institutionenmechanik, kriegswirtschaftlichen Modellen entnommen, sprechen. In ihrer militaristischen Variante dominierten Vorstellungen von einem Stab-Linie-Organigramm.

Wie der Staat in Kategorien der Maschine verstanden, so wurden auf die Gesellschaft Kategorien der Fabrik angelegt: Die gesamte Gesellschaft werde „ein Büro und eine Fabrik mit gleicher Arbeit und gleichem Lohn $\operatorname{sein}^{\alpha 33}$. Die Willensübertragung von der Partei auf das nicht hinreichend bewußte Proletariat sollte in $\mathrm{Ge}$ stalt von Transmissionsriemen über die Gewerkschaften erfolgen. Sie sollten durch geeignete und kontrollierte Rekrutierung sals Schule des Kommunismus und der Leitungstätigkeit" und als "Quell, dem unsere ganze Macht entspringt" funktionieren ${ }^{34}$. Auch die Partei und ihr Apparat konnten symbolisch als Räderwerk mit Keilriemen vorgestellt werden ${ }^{35}$.

Als dieses Modell nicht oder nur sehr ungenügend funktionierte, sollte es durch Kampagnen, eine Flut von Vorschriften, durch Gewalteinsätze und schließlich durch Säuberung ${ }_{n}$ auf Linie ${ }^{\star}$ gebracht werden. Reflexartig wurden für das mangelhafte Funktionieren der Sowjet- (und Partei-)Apparate Sabotage der , kleinbürgerlichen Elemente", der alten Bürokraten aus der Zarenzeit verantwortlich gemacht, die in der Tat die neuen Verwaltungen bevölkerten. Manchmal richtete sich die Kritik aber auch an Aufsteiger aus den Unterschichten, die sich die schlechten

32 Wladimir I. Lenin, Staat und Revolution (1917), in: ders., Werke Bd. 25 (Berlin 1960) 393507.

33 Ebd. 488.

34 Lenin, Referat über die Rolle und die Aufgaben der Gewerkschaften ... (1921), in: ders., Werke Bd. 32 (Berlin 1961) 47.

35 Anonymus, Der organisatorische Aufbau der Kommunistischen Partei (Hamburg 1925). 
Sitten der alten Bürokraten angeeignet hätten und ihre Macht mißbrauchten. Unflexibles und herrisches Verhalten der Behörden, auch Korruption und Mißwirtschaft wurden als "Bürokratismus" ständig kritisiert und beklagt. Er sollte durch Aktivierung der Massen und ihre Teilnahme an der Verwaltung, durch die Rekrutierung aus der Arbeiterklasse und, als auch das nichts half, durch die Rollkommandos der Arbeiter- und Bauerninspektion kontrolliert und zur Raison gebracht werden. Die grundsätzlichen Übel von Bürokratismus aber lagen ganz woanders: im Kampagnenstil und in der Gewalttätigkeit der Politik, im politischen Monopol und in der an keine Verfahrensregeln gebundenen Parteioligarchie wie im permanenten Wechsel der politischen Vorgaben, in der unzureichenden Delegierung von Aufgaben und in der mangelhaften Aufteilung der Kompetenzen. Handlungsund Verfahrensfreiheit der Parteiführung einerseits und die Tendenz der Behörden zu regelhaftem Handeln andererseits standen bis zum Ende der Sowjetunion in einem unaufhebbarem Spannungsverhältnis, das sich im Laufe der Jahrzehnte allerdings sehr unterschiedlich gestaltete. Ein Grundzug sowjetischer Apparate insbesondere zur Zeit Stalins blieb allerdings ihre Anomie, eben Bürokratismus.

Die auf permanente Transformation angelegte Politik mit mangelhafter Funktions- und ohne Gewaltenteilung bedingte, daß auch jenes Maß an Professionalität im Verwaltungshandeln unterschritten wurde, das die zarische Bürokratie bereits erreicht hatte. Was die Revolution an Demokratisierung von Politik und an Massenmobilisierung erkämpft hatte, wurde durch die archaischen und zugleich machtbesessenen Politikvorstellungen ihrer Aktivisten und Gewinner wieder verspielt.

Wegen des durch die Bolschewiki zusätzlich gesteigerten Chaos im Bürgerkrieg verfiel nicht nur Trockij auf die Idee der Arbeitsarmeen. Während des Bürgerkrie-

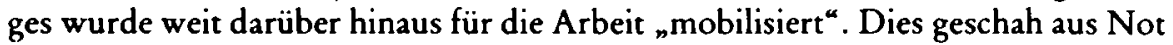
oder als Strafe mit den entsprechenden Androhungen bei "Desertion“. Arbeitsmobilisierung, Arbeitspflicht, orgnabor (Rekrutierung aus den Kolchosen für die Industrie und Großbaustellen), Zwangsarbeit in unterschiedlicher Gestaltung und nicht zuletzt die Zusammenfassung der Arbeiter und Kolchosbauern in Brigaden - all dies deutet auf ein sehr spezifisches Verständnis von Arbeit und Organisation. Mit der viel beschworenen Kollektivität verband es Kontrolle mit einem Stab-Linie-Organigramm, das seine militärische Herkunft kaum verleugnen kann. Allerdings lagen obsessive Vorstellungen von Arbeitsorganisation und -kontrolle zumeist sehr weit entfernt von den realen Verhältnissen in der Arbeitswelt. Sie wurde geplagt von ungesteuerter Fluktuation und erheblicher Ineffizienz. Der Organisationsfetischismus, wie er sich besonders drastisch im Kolchos austobte, war nur die Kehrseite einer selten beherrschten Realität. Erst mit dem Übergang zur Kriegswirtschaft seit Ende der dreißiger Jahre wurde mit der Durchsetzung von Arbeitsbüchern, der Bindung auch der Arbeiter und Angestellten an ihre Unternehmen, der Wohnortkontrolle und den Inlandspässen so etwas wie eine regulierte Ordnung durchgesetzt. Dies geschah allerdings um den 
Preis einer hohen Strafanfälligkeit der Bevölkerung, die millionenfach für die Verletzung oft kaum einzuhaltender Vorschriften kriminalisiert wurde ${ }^{36}$.

\section{Die permanente Feindmarkierung}

$\mathrm{Zu}$ keiner Zeit war die Anzahl der Insassen in Arbeitsbesserungslagern und -kolonien, der Sträflinge in Arbeitsarmeen und Sonderkontingenten wie der Verbannten in Sondersiedlungsgebieten so hoch wie 1940 und dann wieder nach $1945^{37}$. Diese Situation spiegeln die Statistiken für eine Zeit, als es kaum politische Gegner in der Sowjetunion gab, als der Klassenfeind im Innern und auch der äuBere Feind (nach 1945) besiegt waren. Die permanente Produktion von Kriminellen und von Staatsfeinden ( ${ }_{n}$ Konterrevolutionären ${ }^{\alpha}$ ) hatte solche Formen und ein solches Ausmaß angenommen, daß von einer zur Routine gewordenen Strafpolitik ausgegangen werden muß. Gruppen und Individuen wurden im Fließbandverfahren entweder zu Kriminellen oder zu Feinden erklärt.

Die Sucht, Feinde zu markieren und zu „produzieren“, hatte sich sehr bald nach der Oktoberrevolution gezeigt. Schon Lenins Sprache ist durch ihre extreme Polarisierung gekennzeichnet. Feinde wurden bei Lenin nach „objektiven“ Kriterien geschaffen: entweder durch die Klassenlage oder durch falsche Ideen, die als Ausdruck feindlicher Klassen galten. So war der richtige revolutionäre Impuls der Volkstümler (narodniki) falsch orientiert, weil ihre Ideen die unentschiedene Klassenlage der Bauern (zwischen Proletarisierung und Verbürgerlichung) widerspiegelten ${ }^{38}$. Im Konfliktfall stand der Gegner „objektiv“ auf Positionen des Klassenfeindes, selbst wenn er Proletarier war, weil er z.B. kleinbürgerlichen Ideen huldigte oder „objektiv“ - ohne Ansehen seines realen Verhaltens - Positionen des Klassenfeindes repräsentierte. Aus dieser Sichtweise folgte konsequent eine summarische Strafpolitik: Geiselnahme, Sippenhaft, Diskriminierung oder Bestrafung nach kollektiven Merkmalen, die sich im Laufe der Jahrzehnte wandeln sollten. Der Bürgerkrieg und die innerparteilichen Auseinandersetzungen nach 1923/24 haben diese Auffassungen in der Partei zur Norm werden lassen. Alle Individuen oder Gruppen, die sich dem bolschewistischen Projekt entgegenstellten, ihm im Wege standen oder zu stehen schienen, wurden zum Objekt hemmungsloser verbaler oder auch tätlicher Aggression, der Verdächtigung und Stigmatisierung mit jeweils sehr unterschiedlichen Folgen. Die Feindmarkierung ging auch

36 William G. Rosenberg, The Social Background to Tscktran, in: Diane P. Koenker u.a. (Hrsg.), Party, State, and Society in the Russian Civil War (Bloomington, N.D. 1989) 349373; ders. u. a. (Hrsg.), Social Dimensions of Soviet Industrialization (Bloomington, Ind. 1993); Oleg W. Chlewnjuk, Das Politbüro. Mechanismen der politischen Macht in der Sowjetunion der dreißiger Jahre (Hamburg 1998). Auch: Beyrau, Petrograd.

37 Stephan Merl, Das System der Zwangsarbeit und die Opferzahl im Stalinismus, in: GWU 46 (1995) 277-305, hier 303.

38 Wladimir I. Lenin, Der ökonomische Inhalt der Volkstümlerrichtung ... (1895), in: ders., Werke Bd. 1 (Berlin 1963) $436 \mathrm{ff}$. 
dann nicht verloren, als der Klassenfeind im wörtlichen oder übertragenen Sinne "liquidiert" war. Allerdings wandelten sich die Kriterien, nach denen man zum Feind werden konnte.

Zunächst standen der Klassenfeind und Konterrevolutionär im Vordergrund, dann schon sehr viel unschärfer der Schädling, Saboteur und Diversant, der, sofern er in der Partei agierte, bald als maskierter und als Volksfeind figurierte. Als wiederum „objektive“ Kategorie rückte unter quantitativen Gesichtspunkten seit den späten dreißiger Jahren der nationale Feind in den Vordergrund, also ethnische Gruppen, die deshalb unter Verdacht gerieten, weil sie potentiell in verschwörerischen Verbindungen mit dem konnationalen Ausland stehen könnten (Koreaner, Polen, Deutsche, Finnen und andere). Nach 1941 sollten ihnen weitere Völker in die Verbannung folgen.

Im Wechsel der Kriterien läßt sich zwar eine gleichbleibende pathologische Struktur erkennen, aber auch eine bemerkenswerte Verschiebung der zentralen Paradigmen des bolschewistischen Projekts. Unter politischen Aspekten wird sie seit langem als Übergang von weltrevolutionär-internationalistischen Maximen zu solchen der Machtstaatlichkeit mit unübersehbaren imperialen Attributen gekennzeichnet. Unter kulturellen Aspekten läßt sie sich als Übergang von der revolutionär-experimentellen zu einer Phase der Vorherrschaft eines roten juste milieu kennzeichnen, das eher konventionellen Sekundärtugenden (Familie, Fleiß, Bildung, Professionalität, Ordnung und Hygiene) einen hohen Stellenwert zumaß. Dabei mutierte das weltrevolutionäre zu einem Hierozentrum, mit seinen standardisierten Symbolen und Zeremonien: Moskau als rotes Mekka einer neuen Völkergemeinschaft, die sich durch "heilige" Grenzen gegen eine finstere Umwelt mit ihren inneren Handlangern abgrenzte. Nicht zufällig gelangten in dieser Zeit zwei Begriffe zu besonderer Prominenz: die Maskierung und die Doppelzüngelei (dvurušničestvo). Auffällig ist die Gleichzeitigkeit von Sakralisierung der Binnenwelt und von Dämonisierung des inneren und äußeren Feindes.

Das von Beginn an im bolschewistischen "Text" angelegte doppelbödige Repertoire von rationaler Argumentation und irrationaler, quasi religiöser Inbrunst und Gewißheit, kam in den dreißiger Jahren zu "voller Blüte“. Da Maskierung und Doppelzüngelei nicht einfach als Ausgeburt von Ängsten, Aggressivität und von Vorurteilen gelten konnten, bedurften sie der theoretischen Grundlegung im Konzept des verschärften Klassenkampfes beim Aufbau des Sozialismus. Dieses Konzept war jederzeit abrufbar. Nach Abschluß der Kollektivierung und während der Laufzeit des zweiten Planjahrfünfts (1932/33 bis 1937/38) schob sich diese Semantik deshalb so weit in den Vordergrund öfentlicher Rhetorik, weil das heroisch-prometheische Bild, das die Führung von sich selbst und vom Volk entwarf, mit der Realität nur schwer in Einklang zu bringen war. Maskierung und Doppelzüngelei, heute eher unter dem Begriff der habituellen Schizophrenie gefaßt, lassen sich als Folge der Kluft zwischen Selbstbild und Propaganda auf der einen und dem Alltag auf der anderen Seite interpretieren. Dieser Zustand produzierte immer neue Feinde. Denn die Vernichtung oder Unterwerfung der Klassenfeinde hatte die alten Probleme nicht beseitigen und neue nicht verhindern kön- 
nen: Ineffizienz, Ressourcenverschwendung, Korruptionsketten und Seilschaften, tufta und blat, und die chamäleonartig immer wieder neu auftauchenden Defizite und Flaschenhälse in der Produktion und im Konsum. Maskierung, Doppelzüngelei und Schädlingstätigkeit wurden öffentlich den jetzt als Volksfeinden klassifizierten Personen inner- und außerhalb der Partei angelastet.

In ganz anderer Weise, als es die Partei glaubhaft machen wollte, bildeten Maskieren, Verstellen, Lügen und Verbergen tatsächlich einen konstitutiven Teil der Lebenswelt eines großen Teils der Bevölkerung: Angefangen vom Verbergen der Herkunft über die immer am Rande der Legalität operierenden Wirtschaftsführer bis hin zum standardisierten öffentlichen Reden standen reales Verhalten und vielfach simulierendes Vorzeigen von Gesinnungstüchtigkeit und von Erfolgen jeder Art in einem manchmal lebensgefährlichen Widerspruch, der alltäglich auszuhalten war. Konstruktionsmängel bei einem Flugzeug, Unfälle in der Produktion, Nichterfüllung von Planvorgaben, Druckfehler in den Zeitungen, das Übersehen einer politischen Direktive - all dies konnte den Anlaß liefern für Sabotagevorwürfe und für Denunziationen. So hatten fast alle etwas zu verbergen, selbst wenn viele sich als loyale Bürger oder gar als glühende Anhänger des Systems sahen. Die Beglückung der Menschheit stand in einem bemerkenswerten Gegensatz zu einer wölfischen Realität, welche die Lebenswelt der apparatčiki ebenso erfaßt hatte wie die der Mitläufer und der Opfer in den Verbannungsgebieten wie in den Lagern.

\section{Die Zivilisierungsdiktatur}

Das bolschewistische Projekt stand insofern trotz seiner grobschlächtigen Politik in einer Kontinuität russischer Politik seit Peter I., als es sich unter dem Druck von Rückständigkeit und aufholender Modernisierung sah. Die Überwindung russischen „Asiatentums “ und das selbst gesteckte Ziel, in wenigen Jahren aufholen zu müssen, wofür die westlichen Länder Jahrhunderte benötigt hatten, lassen sich als seine zentralen Kernpunkte verstehen. Dieses Selbstverständnis der Bolschewiki hat über Jahrzehnte v.a. die wirtschafts-und sozialhistorische Forschung geleitet. Auf kulturellem Gebiet war von der „Erziehungsdiktatur" die Rede. Die neucre kulturwissenschaftliche Diskussion arbeitet mit dem Begriff der Selbstzivilisierung (vor und nach 1917) und der Zivilisationsmission der wechselnden Eliten, bezogen vornehmlich auf die russischen Bauern und die nicht-europäischen Völker der Peripherie ${ }^{39}$. Der Appell zur Kultivierung und die ihnen folgenden Maßnahmen richteten sich sowohl an die Masse der immer wieder neu rekrutier-

${ }^{99}$ Jörg Baberowski, Auf der Suche nach Eindeutigkeit. Kolonialismus und zivilisatorische Mission im Zarenreich und in der Sowjetunion, in: JGO 47 (1999) 482-503; ders., Auf der Suche nach Eindeutigkeit. Zivilisatorische Mission, Nationalismus und die Ursprünge des Stalinregimes in Azerbajdzan 1928-1941 (Habil. Tübingen 2000; Stuttgart 2003); Yanni Kotsonis, Making Paesants Backward. Agricultural Cooperatives and the Agrarian Question in Russia, 1861-1914 (New York 1999); Lynne Viola, The Best Sons of the Fatherland. Workers in the Vanguard of Soviet Collectivization (Oxford 1985). 
ten Parteimitglieder wie an die Völker der Sowjetunion einschließlich der Russen. Denn die russischen Bauern galten als nicht viel weniger "rückständig “ als die Nomaden oder die Muslimvölker. Das Spektrum zivilisierender Maßnahmen umfaßte die "Liquidierung" des Analphabetentums, massive Bildungsprogramme, verbunden mit Indoktrination, Ausbildung am Arbeitsplatz ebenso wie den Kampf gegen die Religion und Aufklärungsfeldzüge unter den „kulturell rückständigen "Völkern, womit vor allem Nomaden und Muslimvölker gemeint waren. Auch die Industrialisierung und die Kollektivierung galten als Zivilisationsfortschritt durch die Aneignung einer neuen Arbeits-, Technik- und Organisationskultur.

Zivilisierung und Aufklärung wurden dabei immer mit Kampf und Klassenkampf verbunden. Die Feldzüge gegen alle Arten von Rückständigkeit machten sich vornehmlich an deren angeblichen Repräsentanten fest - in der Terminologie der Bolschewiki: an den Bourgeois und Feudalherren, an der bürgerlichen oder nationaldemokratischen Intelligenz, an Kulaken, Händlern, Clanchefs, Beys und allen Geistlichen. Diese Gruppen wurden stigmatisiert und im wörtlichen wie im übertragenen Sinne „liquidiert“. Dabei bildeten neben den Kulaken und analogen Gruppen bei den Nomaden und Muslimvölkern die Repräsentanten der Religionen zentrale Aggressionsobjekte.

Zunächst war vor allem die Orthodoxe Kirche an der Reihe, seit Ende der zwanziger Jahre aber auch die anderen christlichen Konfessionen, die jüdische Religion, der Islam, der Buddhismus. Selbst der Schamanismus blieb nicht vor „Aufklärung “ verschont. Die Gnadenlosigkeit, mit der die Partei, der Verband der (militanten) Gottlosen und schließlich auch das NKVD gegen Priester, Mullahs, Rabbiner und Schamanen vorgingen, hatte nicht nur mit der oft kompromittierten Stellung vor allem der Hierarchien der Orthodoxen Kirche vor 1917 zu tun, sondern auch damit, daß die Religionen und ihre lebensgestaltenden Sitten und Rituale, vor allem im Islam, als Inbegriff von Rückständigkeit ausgemacht wurden. In den Religionen kamen alternative Deutungssysteme zur Geltung, die dem totalitären Anspruch des Bolschewismus widersprachen. Der Kampf wurde insbesondere bei den „kulturell rückständigen“ Völkern mit der „Emanzipation“ der Frauen verbunden, mit Hygienefeldzügen, Alphabetisierungs- und Bildungsprogrammen - alles Kampagnen, die in den dreißiger Jahren viel Gewalt und Gegengewalt produzierten und nur wenige Erfolge zeitigten. Diese stellten sich aus kommunistischer Sicht erst seit den fünfziger Jahren ein, als weniger gewalttätig, aber effektiver vorgegangen wurde ${ }^{40}$.

Es war die russisch oder europäisch konnotierte Moderne, die den nicht-russischen Völkern des sowjetischen Ostens und Nordens zumeist durch einheimische, allerdings absolut moskauhörige Kader aufgedrängt wurde. Gleichzeitig bekämpfte man unter dem Schlagwort der "Nationaldemokratie“ oder ähnlichen

$40 \mathrm{Jörg}$ Baberowski, Stalinismus an der Peripherie. Das Beispiel Azerbajdzan 1920-1941, in: Manfred Hildermeier (Hrsg.), Stalinismus vor dem Zweiten Weltkrieg (München 1998) 307335. 
Begriffen die als bürgerlich geltenden säkularisierten, zumeist sehr schmalen Bildungsschichten bei den nicht-russischen Völkern - dies in Analogie zu den bürgerlichen Spezialisten unter den Russen ${ }^{41}$.

Destruktion und Zivilisationsmission gingen hier eine eigenartige Verbindung ein. Programmatisch - durch Bildungsprogramme und sozialen Aufstieg unter stalinistischem Vorzeichen - hielt man an der Nationalisierung oder besser an der Indigenisierung des Bolschewismus trotz der faktischen russischen Dominanz in den modernen Sektoren (höhere Bildung, Technik und Industrie) fest. Gleichwohl konnte verkündet werden, daß erst der Bolschewismus die wirkliche Befreiung und Gleichberechtigung aller Völker und zugleich ihre Entwicklung auf eine neue Zivilisationsstufe verwirklicht habe.

Die Kultur wurde nach vielen Experimenten und Auseinandersetzungen einem sehr utilitaristisch verstandenen Erziehungsauftrag unterworfen. Primär diente sie spätestens seit Anfang der dreißiger Jahre der Selbstrepräsentation des sich formierenden "roten“ juste milieu, aber sie behielt gleichwohl den Auftrag, einen kultivierten Konsumenten zu erziehen. Der Gebrauch von Kunst, Theater, Film und Literatur sollte bilden, aber auch für die Arbeit motivieren. Unterhaltungskunst in ihren kommerziellen Varianten - so z.B. der Kriminalroman - wurde ganz bildungsbürgerlich bekämpft, auch wenn sie sich in Nischen etablierte oder sozialistisch vereinnahmt wurde. Der Shakespeare lesende kolchoznik blieb allerdings ein bildungsbürgerliches Phantasieprodukt. Kultumost' (Kultiviertheit) ${ }^{42}$ wurde zu einem zentralen Schlagwort, das eine Brücke herstellte zum kulturträgerischen Ethos der vorrevolutionären Intelligenz. Soweit sie die Kampagnen und den Terror überstanden hatte, durfte sie nun auch konservativ-patriotische Werte in Umlauf bringen, wie es z. B. bürgerlichen Historikern erlaubt wurde. Auch andere Elemente „zivilisierender“ Art wurden unter Stalin wieder hoffähig. Dies galt nicht zuletzt für den bis Anfang der dreißiger Jahre ausschließlich negativ bewerteten russischen Kolonialismus.

Schon seit den zwanziger Jahren existierten in den verschiedensten Wissensfeldern mit je unterschiedlichem Gewicht Erziehungs- und Disziplinierungsdiskurse, denen es um den funktionstüchtigen, ordentlichen und disziplinierten Bürger und Produzenten ging. In diesem Sinne ist die Rezeption und Propagienung von Taylorismus und Fordismus, von Makarenkos Abrichtungspädagogik, aber auch der außerwissenschaftliche Diskurs um Pavlovs Physiologie oder die aggressive Durchsetzung von Lysenkos neo-lamarckistischer Agrobiologie zu verstehen. Alle diese Konzepte gingen von der Erziehbarkeit und Abrichtung als leitendem Prinzip aus, das in dieser oder jener Form auf die Transformation von Natur, Mensch und Gesellschaft setzte ${ }^{43}$.

41 Terry D. Martin, The Affirmative Action Empire: Nations and Nationalism in the Soviet Union (Ithaca, London 2001) 249ff., $273 \mathrm{ff} ., 309 \mathrm{ff}$.

42 Vadim Volkov, The Concept of "kulturnost'“ Notes on the Stalinist Civilizing Process, in: Sheila Fitzpatrick (Hrsg.), Stalinism. New Directions (London 2000) 210-230.

${ }^{43} \mathrm{Vgl}$. die Beiträge von Torsten Rüting, Kirill Rossijanow, Hans-Walter Schmubl u. Eduard Koltschinski, in: Dietrich Beyrau (Hrsg.), Im Dschungel der Macht. Intellektuelle Professio- 
Die "sozialistische Rekonstruktion" wurde als prometheisches Unternehmen gesehen, das nur im Kampf gegen die Natur, gegen Rückständigkeit und die Böswilligkeit innerer und äußerer Feinde durchgesetzt werden konnte. Entsprechend diesem Auftrag mußten die Parteikader geschult, indoktriniert, manchmal geradezu konditioniert werden. Daraus ergaben sich Verhaltenszwänge, Rituale und Codes, die spätestens seit den zwanziger Jahren immer wieder in Versammlungen und durch das Vorbild der Publizistik eingeübt wurden. Der Kampf gegen alle Arten von "Abweichung ", der Kulturfeldzug, die Schauprozesse, die permanenten Säuberungen und Überprüfungen durch Kommissionen der Partei oder gelegentlich auch durch die Parteibasis, die akklamierenden Resolutionen in den Betrieben und nicht zuletzt die ständige Abfolge von Kampagnen inner- wie außerhalb der Partei schufen ein Konditionierungsfeld, in das weit über die Parteimitgliedschaft breite Kreise der Bevölkerung aktiv oder passiv einbezogen wurden. Vor dem Hintergrund bolschewistischer Wort- und Dogmengläubigkeit kam der öffentlichen Rede ein hoher Stellenwert zu. Schon die Revolution von 1917 war nicht zuletzt ein Kampf um Worte und Begriffe gewesen ${ }^{44}$. Das Wort galt den Revolutionären als Waffe. Es mußte kontrolliert, bewacht und gesteuert werden. In der bolschewistischen Rede: ${ }_{n} . .$. wie die revolutionäre Macht nicht zulassen kann, daß jeder Hinz und Kunz im Besitz von Revolvern und Maschinengewehren ist, ... so darf der Staat auch nicht die Freiheit gedruckter Propaganda zulassen“, so 1921 der Volkskommissar für Kultur und Bildung A. V. Lunačarskij ${ }^{45}$. Bezeichnend ist hier nicht nur das unbekümmerte Bekenntnis zur Zensur, sondern ebenso, daß jede Art des öffentlichen Textes - hier war von Belletristik die Rede als Propaganda verstanden wurde. Daher müssen die Rhetoriken des permanenten Bekenntnisses, der ritualisierten Militanz, die Kritik und die Selbstkritik, die Schuldbekenntnisse der Angeklagten, die Reueerklärungen "abweichlerischer “ Parteigenossen, die manchmal geradezu magische Umdeutung von Realität in Gestalt eines ganz herrschaftskonformen Monologs, der Dialog und Authentizität simulierte, als verbale Varianten von Selbstkonditionierung verstanden werden. Besonders exaltierte Ausmaße sollten diese rhetorischen Exzesse um 1930 erreichen, als die "Umschmiedung" zu einem zentralen Begriff der Selbsttransformation von Aktivisten, Intellektuellen und Produzenten wurde.

In der Zeit des sog. „Großen Terrors“ seit etwa 1935 lassen die überlieferten Protokolle der Marathon-Versammlungen auf allen Ebenen der Partei, in Betrieben und gesellschaftlichen Organisationen den unausweichlichen $Z_{\text {wang einer }}$ Psychotechnik erkennen, die zugleich Unterwerfung einüben und für die Aufgaben der Partei konditionieren sollte. Diese Technik zielte darauf ab, immer wieder aufs neue das Über-Ich der Partei zu beschwören - „das Gesicht der Partei zu-

nen unter Stalin und Hitler (Göttingen 2000) 319-339, 340-359, 360-377, 84-105; im folgenden zitiert: Beyrau, Dschungel der Macht. Torsten Rüting, Pavlov und der Neue Mensch. Diskurse über Disziplinierung in der Sowjetunion (München 2002).

4 Roger Petbybridge, The Spread of the Russian Revolution. Essays on 1917 (London 1972).

45 Zitiert nach Karl Eimermacher (Hrsg.), Die sowjetische Literaturpolitik 1917-1932 (Bochum 1994) 192. 
wenden ". Es mußten eigene Fehler öffentlich bekannt und Fehler der Genossen gnadenlos entlarvt und seziert werden. Auf diese Weise wurde nicht nur die Autorität der Partei als oberste moralische Instanz verinnerlicht, sondern jeder Einzelne sollte sich auf diese Weise erziehen oder erzogen werden, um sich den Zielen der Partei und des bolschewistischen Projekts als würdig zu erweisen ${ }^{46}$.

Neben die rhetorische Akrobatik trat bald - sehr viel massenwirksamer - die Arbeit als Medium der Umerziehung von Kriminellen, Prostituierten, Arbeitsscheuen und vor allem von klassenfremden und klassenfeindlichen Gruppen. Im Begriff der Arbeitsbesserungskolonien und Arbeitsbesserungslager kommt dieser Glaube an die Umerziehung durch Arbeit zum Ausdruck. Diese Bezeichnungen blieben auch dann noch bestehen, als seit Mitte der dreißiger Jahre die „Besserung " der Sträflinge propagandistisch bestenfalls eine marginale Rolle spielte und die rhetorischen Exzesse zum „Zwitschern“ (Solženicyn) verkamen"7.

\section{Technikgläubigkeit und Standardisierung}

„Sozialismus ist der organisierte Kampf der Menschheit mit der Natur für die vollkommene Unterwerfung unter die Vernunft", hatte A. V. Lunačarskij schon vor der Revolution verkündet ${ }^{48}$. Dem bolschewistischen Projekt unterlag als wichtige Unterströmung immer ein technokratisches Element. Dabei fürchtete man zugleich jene Gruppen bürgerlicher Ingenieure und Techniker, die sich zu den eigentlichen Fürsprechern einer Technokratie aufgeworfen und damit durchaus politische Ansprüche verbunden hatten ${ }^{49}$. Es war nicht nur Propaganda, wenn die bolschewistische Führung angesichts einer von irrationalen kapitalistischen Interessen befreiten Gesellschaft glaubte, den Naturwissenschaften und der Technik besonders gute Entfaltungsmöglichkeiten zu bieten. Kommunismus als Sowjetmacht plus Elektrifizierung enthielt im metaphorischen wie im wörtlichen Sinn den Appell an sich selbst wie an die technische Intelligenz, das rückständige Rußland, seine Menschen und die Gesellschaft wie auch die Landschaften und die Natur nach Gesichtspunkten technischer Rationalität umzugestalten. Nicht zuletzt in das besiegte Dorf sollte "Licht" getragen werden. Neben einer sozialrevolutionären enthielt das bolschewistische Projekt somit auch von Anfang an Kom-

46 Siche die Materialicn des Februar-März-Plenums des ZK von 1937, in: Voprosy istorii (1992-95); zu den deutschsprachigen Literaten vgl. Reinhard Müller (Hrsg.), Die Säuberung. Moskau 1936. Stenogramm einer geschlossenen Parteiversammlung (Reinbek 1991).

47 Joachim Klein, Belomorkanal. Literatur und Propaganda in der Stalinzeit, in: Zeitschrift für Slavische Philologie 55 (1995/96) 53-98; Alla Ju. Gorćeva, Pressa GULAGA (1918-1955) (Moskau 1996). Dietrich Beyrau, Einführung in "Im Dschungel der Macht ${ }^{*}$, in: ders., Dschungel der Macht 9-44, hier $29 \mathrm{f}$.

48 Zitiert nach James McClelland, Utopianism versus Revolutionary Heroism in Bolshevik Policy: The Proletarian Culture Debate, in: Slavic Review 39 (1980) 403-25, hier 414.

${ }^{49}$ Kendall E. Bailes, Technology and Society under Lenin and Stalin (Princeton, N.J. 1978). 
ponenten einer Sozial- und Technikplanung, deren rigoroser Disziplin sich das Individuum unterzuordnen hatte.

Im Vergleich zur Zivilisationskritik vor allem in Deutschland fällt der ungebremste Fortschrittsoptimismus im sowjetischen Rußland auf. Er war keineswegs beschränkt auf die bolschewistischen Zirkel. Den Hintergrund für die breite Ak-

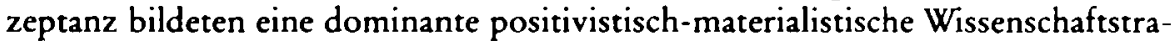
dition und eine schon vor 1914 in der populären Literatur verbreitete Wissenschafts- und Aufklärungsgläubigkeir ${ }^{50}$. Sie hatte offenbar jenen Platz besetzt, den die Religion nicht mehr ausfüllen konnte. In den zwanziger Jahren wurden Taylorismus und Fordismus enthusiastisch rezipiert, kamen sie doch dem eindimensionalen Menschenbild vom neuen Arbeiter entgegen. Es war die Beschränkung auf seine Funktionen als "Schräubchen “ im Betrieb und in der Gesellschaft, die den ersten anti-utopischen Roman Evgenij Zamjatins provozierte ${ }^{51}$.

In der Stalinzeit wurde Literatur über Technik und Wissenschaften - neben dem "Kurzen Lehrgang der KPdSU“ - in Massenauflagen verbreitet. Man kann hier durchaus Komponenten eines Technik- und Wissenschaftskultes erkennen. In der metaphorischen Sprache der Zeit verband er sich mit dem Kampf gegen die Natur, gegen das Dunkle und Naturhafte im Menschen, vor allem bei den Bauern und "kulturell rückständigen“ Völkern, und gegen alle Spielarten von Religion. Die Aneignung der Technik galt als prometheischer Kampf. Der proletarische Sturm auf die bürgerliche Festung Wissenschaft war verbunden mit der Unterwerfung - „Liquidierung “, Neutralisierung, Umerziehung - der bürgerlichen Ingenieure und Wissenschaftler und der Massenrekrutierung für die gigantischen Baustellen und Industrieprojekte. Hier verschmolzen Klassenkampf und der Aufbruch zu neuen Ufern durch Umgestaltung der Gesellschaft und ihrer Menschen. Diese "Rekonstruktion" war verkörpert in den im ersten Fünfjahrplan in Angriff genommenen großen Industrie- und Erschließungsprojekten. Sie kombinierten mit je unterschiedlichen Anteilen Zwangsarbeit unter primitivsten technischen (und häufig mörderischen) Bedingungen und den Einsatz amerikanischer Blaupausen und Großtechnik, die oft mit Hilfe amerikanischer und deutscher Ingenieure, Techniker und Facharbeiter in Rußland implantiert wurden und von den sowjetischen Fachleuten adaptiert werden mußten ${ }^{52}$.

5c Alexander Vucinich, Social Thought in Tsarist Russia. The Quest for a General Science of Society, 1861-1917 (Chicago 1976); Jeffrey Brooks, When Russia Learned to Read. Literacy and Popular Literature, 1861-1917 (Princeton, N.J. 1985).

51 Melanie Tatur, Taylorismus in der Sowjetunion (Frankfurt a.M. 1983); Walter Süss, Die Arbeiterklasse als Maschine. Ein industriesoziologischer Beitrag zur Sozialgeschichte des Stalinismus (Berlin 1985); Kendall E. Bailes, Alexei Gastev and the Controversy over Taylorism, 1918-1924, in: Soviet Studies 29 (1977) 373-394; Jewgenij Samjatin, Wir. Roman (Köln 1958).

52 Antony C. Sutton, Western Technology and Soviet Economic Development, Bd. 1-2 (Stanford 1968-71); Stephen Kotkin, Magnetic Mountain; Paul R. Josephson, "Projects of the Century" in Soviet History: Large Scale Technologies from Lenin to Stalin, in: Technology and Culture 3 (1995) 519-559. 
Hier schien sich zu verwirklichen, was Lenin in seinem Plan zur Elektrifizierung (GOELRO) erst als Vision ausgemalt hatte. Schon hierbei ging es um mehr als nur um eine technische Modernisierung. Auch bei Lenin stand der erzieherische und sozialtechnische Aspekt durchaus im Vordergrund: die Nutzung, Umgestaltung und Unterwerfung der Natur sowie die Aneignung technischer und organisatorischer Verfahren als Instrumente nun sozialistischer Zivilisierung ${ }^{53}$. In den dreißiger Jahren waren es die „alten“ Menschen, die an den Aufgaben wuchsen, sich "umschmiedeten " und sich zumindest perspektivisch in "neue Menschen" verwandelten.

Die Attraktivität von Technik - weniger von Naturwissenschaften - zeigte sich auch darin, daß dem Ingenieur als Gestalter der neuen Welt ein besonderes Prestige zufiel. Er besetzte in der Wirtschaft - aber auch in der Partei - jene ubiquitäre Rolle, die in den Marktgesellschaften von Juristen eingenommen wurde. Die Parteielite unter Stalin rekrutierte sich daher zum größten Teil aus Aufsteigern, die wenigstens nominell - technische Ausbildung mit Parteischulung verbanden. Die Wahrnehmung sozialer Probleme als solche technischer und sozialer Planung einschließlich der Feindbekämpfung als "soziale Prophylaxe" - bildete einen zentralen Bestandteil des bolschewistischen Projekts. Nach dem Ende der revolutionären Sturm- und Drang-Periode und nach dem Tode Stalins transformierte es sich zu evolutionärer Entwicklungs- und Erschließungspolitik mit einem hohen $\mathrm{Ma} ß$ an gewollter Standardisierung und Nivellierung der Lebensverhältnisse ${ }^{54}$.

Das technokratische Ethos, das keineswegs mit der Herrschaft einer Expertokratie verwechselt werden darf, zeigte sich auch in der neuen Epochenteilung nach Fünfjahrplänen. In Jahrespläne oder gar in noch kürzere Vorgaben umgesetzt, stellten sie in der Propaganda, aber auch in dem ständigen Kampf um Planerfüllung eine scheinbar nach ehernen Gesetzen funktionierende Rationalität dar. Die Erfüllung oder Nichterfüllung von zumeist quantitativen Planvorgaben wurde zum Gradmesser für Belohnung, Maßregelung oder gar Bestrafung (unter Stalin).

Die Planwirtschaft war in erster Linie eine Geschichte von Großprojekten, der "Projekte des Kommunismus“. Sie reicht von Lenins Plan zur Elektrifizierung als erstem Versuch, Planmethoden auszuprobieren, über die immer als Medien der Mobilisierung gedachten Großprojekte der Stalinzeit bis hin zu ntalins Plan zur Umgestaltung der Natur" nach dem Krieg ${ }^{55}$. Weniger in den Vordergrund gerückt wurden die militärischen Anstrengungen, hier vor allem der Panzer- und der Flugzeugbau, die schon vor dem Krieg erhebliche Anteile an den Investitionen,

53 Heiko Haumann, Beginn der Planwirtschaft. Elektrifizierung, Wirtschaftsplanung und gesellschaftliche Entwicklung Sowjetrußlands 1917-1921 (Düsseldorf 1974); Karl Schlögel, Jenseits des Großen Oktobers (Berlin 1988) $277 \mathrm{ff.}$

${ }^{4}$ Beyrau, Intelligenz 145ff.; Wolfgang Teckenberg, Gegenwartsgesellschaften: UdSSR (Stuttgart 1983) 279ff.

55 Klaus Gestwa, Herrschaft und Technik in der spät- und nachstalinschen Sowjetunion, in: Osteuropa 51 (2001) 171-193. 
wissenschaftlichen Kapazitäten und Arbeitskräften banden und entstehen ließen, was später als "militarisierter Sozialismus" bezeichnet werden sollte ${ }^{56}$.

\section{Ausblick und Vergleich}

Es liegen bereits mehrere Versuche vor, unter verschiedenen Gesichtspunkten das NS-Regime und das Stalinsystem zu vergleichen ${ }^{57}$. Die Gewaltpolitik und exzessive Feindmarkierung stehen hierbei oft im Vordergrund. Für beide Systeme in ihrer Bewegungs- wie in der Phase ihrer Institutionalisierung gilt, daß sie radikale Gesellschaftsentwürfe unter Zeitdruck verwirklichen wollten. Die Gesellschaft wurde auf diese Weise zum Experimentierfeld. In einem Fall waren es rassistischbiologistische Kriterien, in dem anderen Kriterien der sozialistischen Tradition, welche die Vorstellungen und die Handlungen leiteten: hier die Schaffung eines "gesunden" Volkskörpers und die Herrschaft der germanischen Rasse, dort die Etablierung einer von Ausbeutung und Klassenantagonismen befreiten kommunistischen Gesellschaft. Alle Versuche, die Umsetzung dieser Visionen auf einen Begriff - politische Religion, Ideologie, Utopie - zu bringen, scheitern am Widerspruch zwischen der Enge dieser Begriffe und der Vieldeutigkeit und Vielschichtigkeit von Realitäten, die sie einfangen wollen. Politische Religion ist vornehmlich auf die kultischen Elemente fixiert, die nicht notwendigerweise religiöse Inhalte transportieren. Ideologie erfaßt lediglich die im Bolschewismus vergleichsweise kohärente intellektuelle Dogmatik, in der sich das bolschewistische Vorhaben aber nicht erschöpft. Utopie meint die zeit- und raumentrückte Vision ohne Handlungsrelevanz. Deshalb bevorzuge ich den offeneren Begriff des Projektes.

Er akzeptiert die Bedeutung von Ideen als Weichenstellern und betont ihre Wirkungsmacht sowohl in Gestalt von Realitätsdeutung als auch in der Struktur von Entscheidungen und Handlungen. Das Ensemble bolschewistischer Ideen wurde zu physischer und psychischer Gewalt, die den Alltag und die Lebensweise der Bevölkerung maßgeblich formte. Zugespitzt läßt sich im sowjetischen Fall von einem „Vollzug" von Vorstellungen und Entwürfen einer ganz neuen Gesellschaft sprechen. Die Ergebnisse waren unvermeidlich andere, als die Initiatoren erwartet hatten. Dies gilt selbst für die Markierung der Feinde, die - jenseits ihrer subjek-

56 Lennart Samuelson, Soviet Defense Industry: Tukhachevskii and Military Industrial Mobilization (Stockholm 1996); Sally Stoecker, Forging Stalin's Army: Marshall Tukhachevskii and the Politics of Military Innovation (Boulder, Colorado 1998). Siehe auch die Beiträge unter "Militarisierter Sozialismus", in: Initial 8 (6/1997).

57 Zygmunt Bauman, Dialektik der Ordnung. Die Moderne und der Holocaust (Hamburg 1994); Matthias Vetter (Hrsg.), Terroristische Diktaturen im 20. Jahrhundert (Opladen 1996); Ian Kershaw, Moshe Lewin (Hrsg.), Stalinism and Nazism: Dictatorship in Comparison (Cambridge 1997); Dietrich Beyrau, Nationalsozialistisches Regime und Stalin-System. Ein riskanter Vergleich, in: Osteuropa 50 (2000) 709-720; ders., Einführung in „Im Dschungel der Macht ${ }^{\alpha}$ 9-44; Leonid Luks (Hrsg.), Rußland und Deutschland im 19. und 20. Jahrhundert (Köln 2001). 
tiven Einstellungen - dem Zukunftsprojekt aus der Sicht der „Gärtner ${ }^{\text {“ }}$ (Z. Bauman) entgegenstanden: auf der einen Seite rassisch und biologisch "minderwertige" Gruppen und Völker, auf der anderen Seite Klassen- und Volksfeinde sowie feindliche Ethnien. Beide Fälle kannten zudem ein hohes Maß an zufälligen Opfern, eine Folge der Dynamik enthemmter Gewaltpolitik.

In welchem Maße läßt sich von der Realisierung des Utopischen sprechen? Vor und während des Ersten Weltkrieges grassierten mit jeweils unterschiedlicher Breitenwirkung Kulturpessimismus und Zivilisationskritik, die sich in Rußland an apokalyptischen Visionen festmachten. Vor allem literarische und philosophische Zirkel deuteten den Zusammenbruch Rußlands nach diesen Kategorien - als Herrschaft des Antichrist, als Sieg satanischer Triebe in der Bevölkerung, metaphorisch als Sieg der Barbaren oder als Rückkehr der Skythen ${ }^{58}$. Untergangsszenarien einschließlich von Verschwörungstheorien nach dem Muster der „Protokolle der Weisen von Zion "59 blieben mit oder ohne Erlösungshoffnungen den Gegnern der Bolschewiki im Lande oder in der Emigration vorbehalten. Katastrophenerlebnis und Erweckung gelten auch als typische Erfahrungsmuster führender Nationalsozialisten. In Deutschland blieb diese Deutung eingebettet in ein breites Spektrum von Zivilisationskritik und Kulturpessimismus, das nach 1918 unter dem Sammelbegriff der „Konservativen Revolution“ figurierte.

Auf bolschewistischer Seite hingegen wurde die Krise der Moderne primär als Krise von Kapitalismus und Imperialismus gedeutet. Es gab keine Zweifel an der Zukunftsträchtigkeit der industriellen Zivilisation und am Fortschritt. Der Weltkrieg bestärkte eher die revolutionäre Inbrunst und die Bereitschaft zur Gewaltanwendung. Dem Desaster-Syndrom und eventuellen Erweckungserlebnissen der Gegner stand auf bolschewistischer Seite die „sichere Erkenntnis “ gegenüber ${ }^{60}$. Sie teilte die Welt in Verworfene, zu Rettende und Retter ein. Dabei kam auch der Klassenkampf nicht ohne religiöse und heilsgeschichtliche Aufladung aus - häufig unter Verwendung christlicher Metaphorik ${ }^{61}$, weil es im bolschewistischen Projekt um mehr ging als um ökonomische Interessen und eine Neuverteilung der politischen Macht.

58 Iz glubiny. Sbornik statej (1919) (Paris 1967). Dimitri Merescbleowski u. a., Das Reich des Antichrist. Rußland und der Bolschewismus (München 1921); Nikolai Berdjaew, Wahrheit und Lüge des Kommunismus (Baden-Baden 1953); Michael Agursky, The Third Rome: National Bolshevism in the USSR (Boulder, Colorado 1987); Igor Narskij, Volksfrömmigkeit und Kriegserfahrung im Ural 1917-1922, in: Dietrich Beyrau (Hrsg.), Der Krieg in religiösen und nationalen Deutungen der Neuzeit (Tübingen 2001) 165-188.

59 Michael Hagemeister, Sergej Nilus und die "Protokolle der Weisen von Zion", in: Jahrbuch für Antisemitismusforschung 5 (1996) 127-147.

60 James $M$. Rhodes, The Hitler Movement. A Modern Millenarian Revolution (Stanford 1980) $29 \mathrm{f}$.

${ }^{61}$ Mark D. Steinberg, Workers on the Cross: Religious Imagination in the Writings of Russian Workers, 1910-1914, in: The Russian Review 53 (1994) 213-239. Vgl. die verbreiteten und kanonisierten Gedichte von Demjan Bednyj und V. Majakovskij, hier bes. „Lenin“. Auch: Beyrau, Petrograd. 
Die Systemkrise und der Erste Weltkrieg konnten mithin von den radikalisierten Gegeneliten und ihrem Massenanhang ganz unterschiedlich gedeutet werden als Chance oder als Katastrophe. Beide Bewegungen waren in ihren negativen eindeutiger als in ihren positiven Zielbestimmungen. Dabei ist innerhalb der Bewegungen von einer Pluralität der Ziele und Projektionen auszugehen. Im Vergleich zum bolschewistischen konnte sich das NS-Regime auf einen breiten Konsens stützen, sichtbar am viel geringeren Ausmaß an Gewalt gegen die eigene Gesellschaft als dies bei den Bolschewiki und unter Stalin der Fall war. Polarisierung bei den letzteren und Selbstgleichschaltung in Deutschland waren zentrale Merkmale; dies nicht zuletzt deshalb, weil die Ziele der Nationalsozialisten zunächst viel unbestimmter und - bezogen auf die deutsche Bevölkerung - insgesamt integrativer waren als im sowjetischen Fall. Wenn vom Krieg der Bolschewiki und Stalins gegen die eigene Gesellschaft die Rede ist ${ }^{62}$, so läßt sich trotz aller Gewalt gegen Minderheiten in Deutschland vom Bestreben nach innerer Pazifizierung selbst noch im Krieg ausgehen. Die Gewalt tobte sich ungehemmt erst während des Krieges im besetzten Europa gegen alle Juden, Sinti und Roma sowie gegen andere stigmatisierte Gruppen und Völker aus. Das rassistische Experiment mündete in den Krieg und in die Etablierung unterschiedlich organisierter Apartheid in Deutschland und im besetzten Europa.

In der Sowjetunion hingegen entstand eine statusfixierte, unter Stalin extrem hierarchisierte, aber durch die Terrorwellen (und den Krieg) gleichwohl in Bewegung gehaltene Industriegesellschaft. Ihre integrativen Mechanismen ergaben sich durch den Aufstieg zahlreicher Gruppen. Aufstieg konnte hier sowohl die Abwanderung in die Städte, die Nutzung von Bildungsprogrammen, die Einrichtung in privilegierten Feldern der Großstädte, der Groß-, Schwer- und Rüstungsindustrie, in der Wissenschaft und in den Apparaten bedeuten als auch den sozialen Aufstieg in Führungspositionen in Partei, Verwaltung und Wirtschaft. Dabei waren auch die Erfolgreichen durch Terror und Säuberungen gefährdet.

Der Bolschewismus stellte an seine Anhänger, hier besonders an die Parteikader, ungleich höhere intellekruelle und moralische Anforderungen. Daraus ergaben sich Programme und Praktiken der Indoktrination, der Selbstkonditionierung und von Psychotechniken mit weitreichenden Folgen für die Sprache und die Verhaltenscodes. Sie wirkten - jenseits der Einübung von Gewalt - viel einschneidender als bei den Parteimitgliedern der NSDAP. Aus dem überdimensionierten, prometheischen Programm der Bolschewiki ergaben sich die vielfältigen Formen von Denkverboten und der Furcht vor Maskeraden, „Doppelzüngelei“, und der Zwang zu habitueller Schizophrenie und zeitweise zu einer geradezu magischen Umdeutung von Realität, Verhaltensweisen, die an die von Geiseln erinnern.

Dabei bleibt bis heute in der Forschung die Geltung und die Reichweite des bolschewistischen Projektes in den verschiedenen Segmenten der Bevölkerung

62 Nicolas Werth, Ein Staat gegen sein Volk, in: Stéphane Courtois u. a. (Hrsg.), Das Schwarzbuch des Kommunismus. Unterdrückung, Verbrechen und Terror (München 1998) 51-295. 
umstritten oder ist noch nicht ausreichend untersucht, wie z.B. die Reaktionen der nicht unmittelbar Betroffenen auf den Terror und die exzessive Strafpolitik des Regimes. Der Verteidigungskrieg gegen NS-Deutschland scheint eher zu belegen, daß das bolschewistische Projekt, insofern es eine forcierte Modernisierungspolitik betrieb - also nicht spezifisch bolschewistisch war -, zunehmend akzeptiert wurde. Als diese Erwartungen nicht mehr erfüllt werden konnten und das Sowjetsystem auf einem neuen Niveau nur noch den Rückstand zum Westen zu perpetuieren schien, brach es in sich zusammen. Das Projekt mit seinen utopischen Beimischungen hatte sich in seiner militanten Variante seit dem "Großen Vaterländischen Krieg“, aber schließlich auch in seiner evolutionären Variante seit den sechziger Jahren verbraucht. 
